\title{
PELAKSANAAN UPAH MINIMUM REGIONAL (UMR) BAGI PEKERJA ALIH DAYA PADA PT. DELTA DUTA DEWATA DI PT. PLN (PERSERO) DISTRIBUSI BALI ${ }^{*}$
}

\author{
Oleh: \\ Made Ayu Ratih Sanjiwani Giri* \\ I Wayan Wiryawan**

\begin{abstract}
Fakultas Hukum Universitas Udayana
Program Kekhususan Hukum Bisnis
\end{abstract}

\begin{abstract}
ABSTRAK
Perlindungan upah telah diatur dengan jelas di dalam Undang-Undang Nomor 13 Tahun 2003 tentang Ketenagakerjaan, salah satunya adalah adanya upah minimum yang wajib diberikan pengusaha kepada pekerja/buruh. Ketentuan upah minimum yang diatur di dalam setiap Provinsi ataupun Kabupaten/Kota merupakan kewajiban yang harus dilaksanakan oleh pengusaha. Salah satu masalah yang langsung menyentuh para pekerja/buruh adalah rendahnya atau tidak sesuainya pendapatan (Upah) yang diperoleh dengan tuntutan yang untuk memenuhi kebutuhan hidup dan tanggungannya yang semakin meningkat, dan sementara itu gaji yang didapat relatif tetap, menjadi salah satu pendorong protes dari para pekerja/buruhnya. Penulisan ini mengemukakan dua permasalahan, yaitu: bagaimana pelaksanaan Upah Minimum Regional (UMR) terhadap pekerja alih daya di PT. PLN (Persero) Distribusi Bali dan sanksi yang diterima pengusaha jika terdapat penyimpangan pada pelaksanaan Upah Minimum terhadap pekerja alih daya. Metode penelitian yang dipergunakan adalah penelitian hukum empiris, yaitu penelitian ilmiah yang dilakukan dengan melihat

* Penulisan Jurnal ini disarikan serta dikembangkan dari Skripsi yang ditulis oleh penulis atas persetujuan dan bimbingan daei pembimbing skripsi.

* Made Ayu Ratih Sanjiwani Giri adalah Mahasiswa Fakultas Hukum Universitas Udayana, korespondensi dengan penulis melalui Emai: ratihsanjiwani80@gmail.com Udayana.

** I Wayan Wiryawan adalah Dosen Fakultas Hukum Universitas
\end{abstract}


kesenjangan teori dan praktek. Berdasarkan hasil penelitian yang dilakukan terhadap permasalahan, dapat disimpulakn bahwa Pelaksanaan Upah Minimum di PT Delta Duta Dewata belum di terapkan kepada beberapa pekerja alih dayanya, alhasil masih ada beberapa pekerjanya yang masih mendapatkan upah UMK Kota Denpasar Tahun 2017 dan Sanksi yang di terima pengusaha jika terdapat penyimpangan pada pelaksanaan Upah Minimum terhadap pekerja adalah pidana penjara yang paling singkat 1 (satu) tahun dan yang paling lama ialah 4 (empat) tahun dan/atau denda yang paling sedikit Rp 100.000.000,00 dan yang paling banyak Rp 400.000.000,00. Penyelesaian permasalahan yang dilakukan oleh PT Delta Duta Dewata terhadap pekerja alih daya yang masih mendapatkan upah/gaji di bawah upah minimum ialah dengan cara dirundingkan dan di bicarakan dengan baikbaik, permasalahan yang di alami itu di selesaikan dalam waktu kurang lebih 30 hari.

\title{
Kata Kunci : Pelaksanaan, Upah, Pekerja Alih Daya
}

\begin{abstract}
ABTRACK
Wage protection has been clearly regulated in Law Number 13 of 2003 concerning Labor, one of which is the existence of a minimum wage that must be given by employers to workers. Provisions for minimum wages regulated in each Province or Regency / City are obligations that must be carried out by employers. One problem that directly touches workers / laborers is the low or incompatibility of income (Wages) that is obtained by demands that meet the increasing needs of their lives and dependents, and meanwhile the salaries obtained are relatively fixed, becoming one of the drivers of protests from workers / laborers. This writing presents two problems, namely: how to implement the Regional Minimum Wage (UMR) for outsourcing workers at PT. PLN (Persero) Distribution Bali and sanctions received by employers if there is a deviation in the implementation of the Minimum Wage for outsourcing workers. The research method used is empirical legal research, namely scientific research conducted by looking at the gap between theory and practice. Based on the results of the research conducted on the problem, it can be concluded that the Minimum Wage Implementation at PT Delta Duta Dewata has not been applied to several workers outsourcing, as a result there are still a number of workers who still get Denpasar City UMK wages in 2017 and sanctions received by employers if the entrepreneur still giving workers / laborers a wage below the minimum is a prison sentence
\end{abstract}


of at least 1 (one) year and the longest is 4 (four) years and / or a fine of at least $R p$. 100,000,000.00 and a maximum of Rp. 400,000 .000,00. Sloving the problems that PT Delta Duta Dewata carried out against outsourced workers who were still getting a wage below the minimum wage was negotiatied and discussed well, the problems experienced were resolved in approximately 30 days.

\section{Key Words: Implementation, Wages, Outsourcing}

\section{Pendahuluan}

\section{$1.1 \quad$ Latar Belakang}

Untuk melangsungkan kehidupannya, manusia wajib untuk memiliki mata pencaharian hidup, yang dalam konteks status sosial ekonomi disebut sebagai pekerjaan atau profesi. Sebagai subjek hukum yang sentral dalam pelaksanaan hubungan industrial adalah pemerintah, pengusaha, serta pekerja/buruh dan serikat buruh. Ketiga unsur ini menentukan sukses tidaknya pelaksanaan hubungan industrial dalam sistem ketenagakerjaan sehingga perannya haruslah benar-benar dalam situasi dan kondisi yang mendukung pelaksanaan hubungan industrial sesuai filosofi Pancasila dan UUD N RI 1945. Untuk mewujudkan hubungan industrial yang harmonis, UU No. 3 Tahun 2003 tentang Ketenagakerjaan, melibatkan beberapa pihak, yakni: ${ }^{1}$

1. Pekerja/buruh

2. Serikat pekerja

3. Pemberi kerja

4. Organisasi pengusaha

5. Lembaga kerjasama bipartit/tripartit

${ }^{1}$ I Made Udiana. 2016. Kedudukan Dan Kewenangan Pengadilan Hubungan Industrial. Udayana University Press, Denpasar, h. 42 


\section{Dewan pengupahan}

\section{Pemerintah}

Melalui pekerjaan yang dijalaninya itulah seorang pekerja akan mendapatkan jasa dalam bentuk upah. Upah adalah hal yang paling utama dalam ketenagakerjaan, karena tujuan orang bekerja adalah untuk mendapatkan upah yang akan digunakan untuk memenuhi kebutuhan hidupnya. Di tengah situasi perkembangan perekonomian dunia yang berimbas pada terjadinya persaingan bisnis semakin ketat ini, banyak perusahaan berlomba-lomba meningkatkan produktivitasnya, namun dengan berusaha keras menerapkan efisiensi dan efektivitasnya pada masalah keuangan peusahaan. Maka alternatif yang bisa dipilih dengan mencari pekerja yang mau dipekerjakan dengan beberapa syarat yang disepakati dalam suatu perjanjian. Dalam melakukan perjanjian atau kontrak tidak selalu menguntungkan pihak pemakainya, dan dalam keadaan tertentu pula bentuk hukum/perjanjian yang dibuat dapat menyulitkan pemakainya. $^{2}$ Perjanjian kerja inilah yang melandasi adanya hubungan kerja antara pengusaha atau pemberi kerja dengan pekerja/buruh. Hubungan kerja menurut pasal 1 angka 15 Undang-Undang No. 13 Tahun 2003 Tentang Ketenagakerjaan adalah "Hubungan antara pengusahan dengan pekerja/buruh berdasarkan perjanjian kerja, yang mempunyai unsur pekerjaan, upah, dan perintah". ${ }^{3}$ Selain adanya perjanjian kerja antara

${ }^{2}$ I Made Udiana. 2011. Rekontruksi Pengaturan Penyelesaian Sengketa Penanaman Modal Asing. Udayana University Press, Denpasar, h. 11

3 Much. Nuracmad, 2009, Tanya Jawab Seputar Hak-Hak Tenaga Kerja Kontrak (Outsourcing), Visimedia, Jakarta, h.2. 
pengusaha dan pekerja/buruh, kunci utama keberhasilan dalam menciptakan tujuan hubungan industrial yang aman dan dinamis adalah komunikasi. Untuk dapat, emciptakan tujuan hubungan industrial, maka faktor utama adalah interaksi yang positif antara pekerja/buruh dan pengusaha. ${ }^{4} \mathrm{Di}$ Indonesia sendiri sumber hukum perusahaan di atur dalam KUHD, Peraturan perundangundangan yang berkaitan dengan Kebiasaan, dan Yurisprudensi. Adapun sumber utama hukum perusahaan adalah KUHD. ${ }^{5}$

Sulitnya mencari pekerjaan baru, menimbulkan situasi yang tidak enak karena harus menganggur. ${ }^{6}$ Penggunaan sistem pekerja kontrak ini, merupakan sistem perekrutan pekerja dengan membuat kesepakatan diantara kedua belah pihak yaitu pengusaha atau pemberi kerja dan pekerja/buruh. Kata sepakat disini merupakan salah satu syarat sahnya perjanjian yang diatur dalam pasal 1320 Kitab Undang-Undang Hukum Perdata. Kata sepakat sebagai perizinan, yaitu kedua subjek hukum yang mengadakan perjanjian itu harus sepakat, setuju atau seia sekata

${ }^{4}$ I Made Udiana, 2018, Industrialisasi \& Tanggungjawab Pengusaha Terhadap Tenaga Kerja Terlibat Hukum, Udayana University Press, Denpasar, h.65.

${ }^{5}$ Ni Made Pratiwi, 2017, "Hubungan Hukum Perusahaan Induk Berbentuk Perseroan Terbatas Dengan Anak Perusahaan Berbentuk Persekutuan Komanditer”, Acta Comitas, Vol.02, no.01, April 2017, h. 66. https://ojs.unud.ac.id/index.php/ActaComitas/article/view/34258/20614 diakses tanggal 28 Januari 2019 pukul 22.23

${ }^{6}$ Ari Hernawan, 2016, "Keberadaan Uang Pesangon Dalam Pemutusan Hubungan Kerja Demi Hukum Di Perusahaan Yang Sudah Menyelenggarakan Program Jaminan Pensiun”, Kertha

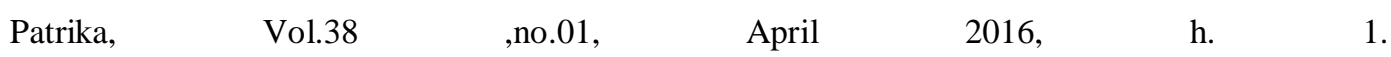
https://ojs.unud.ac.id/index.php/kerthapatrika/article/view/21530 diakses tanggal 28 Januari 2019 pukul 22.30 
mengenai hal-hal pokok dari perjanjian yang diadakan itu. Mereka mengehendaki sesuatu yang sama secara timbal balik. ${ }^{7}$

Selain adanya pekerja kontrak, perusahaan biasanya mengadakan suatu sistem bagi pekerja yang akan di pekerjakan ke anak perusahaan atau perusahaan yang sudah memiliki perjanjian dengan perusahaan satu dengan perusahaan lainnya, yang dinamakan pekerja alih daya. Pekerja alih daya ini sama saja dengan pekerja pada umumnya, bekerja untuk mendapatkan upah. Karena yang menjadi objek dalam perjanjian kerja adalah tenaga yang melekat pada diri pekerja. Atas dasar tenaga yang telah di keluarkan oleh pekerja, maka ia akan mendapatkan upah. ${ }^{8}$

\subsection{Rumusan Masalah}

Berdasarkan dari pemaparan latar belakang diatas, maka dapat ditarik suatu rumusaan masalah adalah sebagai berikut:

1. Bagaimana pelaksanaan Upah Minimum Regional (UMR) terhadap pekerja alih daya di PT. PLN (Persero) Distribusi Bali?

2. Sanksi apakah yang diterima pengusaha jika terdapat penyimpangan terhadap pelaksanaan Upah Minimum terhadap pekerja alih daya?

${ }^{7}$ Subekti, 1987, Hukum Perjanjian, Intermasa, Jakarta, h.17.

${ }^{8}$ Asri Wijayanti, 2009, Hukum Ketenagakerjaan Pasca Reformasi, Sinar Grafika, Jakarta h. 41 . 


\subsection{Tujuan Penelitian}

Untuk mengetahui dan memahami Pelaksanaan Upah Minimum Regional (UMR) terhadap pekerja alih daya di PT. PLN (Persero) Distribusi Bali serta untuk mengetahui dan memahami sanksi apa yang diterima pengusaha jika terdapat penyimpangan terhadap pelaksanaan Upah Minimum terhadap pekerja alih daya.

\section{Isi makalah \\ 2.1 Metode Penulisan}

Metode adalah salah satu instrumen yang menentukan jalannya penyusunan sebuah karya tulis. ${ }^{9}$ Dalam kaitannya dengan itu, maka jenis penulisan hukum yang di gunakan ini adalah hukum empiris. Agar mendapatkan hasil yang mendekati kebenaran ilmiah, maka pada penelitian skripsi ini penulis menggunakan 2 (dua) jenis pendekatan, yakni: pendekatan undang-undang (statue approach), pendekatan fakta (the fact approach).

\subsection{Pembahasan}

\subsubsection{Pelaksanaan Upah Minimum Regional (UMR) Terhadap Pekerja Alih Daya Di PT. PLN (PERSERO) Distribusi Bali}

Sistem pekerja alih daya dibuat agar perusahaan dapat fokus pada kompetensi utamanya dalam bisnis, sehingga dapat berkompetisi dalam meningkatkan income perusahaan. Tujuan ini

9 Suprapto, 2013, "Metodologi Penelitian Imu Pendidikan dan Imu-Ilmu Pengetahuan Sosial (Penelitian Kuantitatif dan Kualitatif Dilengkapi dengan Teknik Pengolahan Data dan Tabel Statistik)", CAPS, Bogor, h. 61. 
baik adanya karena mendapat manfaat simbiosis mutualisme, yaitu saling menguntungkan. Namun pada pelaksanaannya, pengalihan ini kadang menimbulkan beberapa permasalahan terutama ketenagakerjaan.

Berdasarkan Pasal 1 ayat (3) Peraturan Menteri Tenaga Kerja Dan Transmigrasi Republik Indonesia Nomor 19 Tahun 2012 Tentang Syarat-Syarat Penyerahan Sebagian Pelaksanaan Pekerjaan Kepada Perusahaan Lain disebutkan bahwa Perusahaan penyedia jasa pekerja/buruh adalah perusahaan yang berbentuk badan hukum Perseroan Terbatas (PT) yang memenuhi syarat untuk melaksanakan kegiatan jasa penunjang perusahaan pemberi pekerjaan.

Agar dapat mewujudkan penghasilan yang layak, dibutuhkan kerja sama yang baik dengan beberapa perusahaan lain untuk mengerjakan sebagian pekerjaan di lingkungan PT. PLN (Persero) agar perusahaan dapat lebih fokus pada pencapaian target kinerja perusahaan yang semakin baik. Namun ada kala terjadi sesuatu perselisihan antara pemberi kerja dengan perusahaan alih daya yang dapat merugikan perusahaan seperti menurunnya kinerja, penunggakan pembayaran hak-hak normatif, dan sebagainya.

Kebijakan upah minimum adalah sebagai upaya mewujudkan penghasilan yang layak bagi pekerja/buruh, dengan mempertimbangkan peningkatan kesejahteraan pekerja/buruh tanpa mengabaikan produktivitas dan kemajuaan perusahaan serta perkembangan perekonomian pada umumnya.

Pengertian upah minimum menurut Pasal 1 angka 1 Peraturan Menteri Tenaga Kerja Nomor : PER-01/MEN/1999 
tentang Upah Minimum adalah upah bulanan terendah yang terdiri dari upah pokok termasuk tunjangan tetap. Berdasarkan Pasal 89 ayat (1) Undang-Undang Nomor 13 Tahun 2003 Tentang Ketenagakerjaan, upah minimum terdiri atas :

a. Upah Minimum berdasarkan wilayah provinsi atau kabupaten/kota;

b. Upah Minimum berdasarkan sektor pada wilayah provinsi atau kabupaten/kota

Pelaksanaan Upah Minimum Kabupaten/Kota (selanjutnya disebut UMK) ini di Kota Denpasar berdasarkan Peraturan Gubernur No. 65 Tahun 2017, menunjukan bahwa UMK Kota Denpasar untuk tahun 2018 adalah sebesar Rp 2.363.000,00.

Berdasarkan wawancara dengan $\mathrm{Ni}$ Made Leci, yang menjelaskan bahwa PT. Delta Duta Dewata sebelumnya sudah mengadakan sebuah perjanjian pemborongan pekerjaan dengan PT. PLN (Persero) Distribusi Bali yang akan memborongkan pekerjaan untuk Pemeliharaan Gedung Kantor PT. PLN (Persero) Distribusi Bali kepada PT Delta Duta Dewata dan perusahaan yang bersangkutan setuju untuk menerima pemborongan pekerjaan Pemeliharaan Kebersihan Gedung kantor PT. PLN (Persero) Distribusi Bali. Dan untuk mengenai upah, karena perusahaan PT. Delta Duta Dewata berkedudukan di wilayah kota Denpasar, sehingga PT. Delta Duta Dewata wajib mengikuti ketentuan UMK wilayah kota Denpasar yaitu sebesar Rp 2.363.000,00 untuk tahun 2018 yang telah diatur pada Peraturan Gubernur No. 65 Tahun 2017 (Wawancara 19 November 2018).

Pada kenyataannya perealisasian tentang upah minimum pekerja masih saja ada yang tidak dilaksanakan sesuai dengan isi 
kontrak kerja. Perusahaan masih memberi upa Hasil Surat Pengawasan Aspek Ketenagakerjaan Triwulan III Tahun 2018 dengan Nomor : 323/SDM.06.01/BISDMO/2018, yang ditujukan kepada Vendor dari PT. PLN (Persero) Distribusi Bali, yang menyatakan bahwa berdasarkan slip gaji atas nama Ni Made Suerti dan Ni Luh Wati bulan Mei 2018 Realisasi pembayaran Upah masih menggunakan UMK Tahun 2017 dengan nominal Rp 2.173.000,00 (UMK Kota Denpasar) dan belum dilakukan penyesuaian UMK Tahun 2018.

Tentu permasalahan ini bertentangan dengan Peraturan Menteri Tenaga Kerja Nomor : PER-01/MEN/1999 jo. Keputusan Menteri Tenaga Kerja dan Transmigrasi Nomor : KEP226/MEN/2000, Pasal 14 ayat (1), bahwa upah minimum berlaku untuk semua status pekerja, baik tetap, tidak tetap, maupun percobaan.

Hasil wawancara dengan Ni Luh Wati, dengan status sebagai pekerja alih daya. Masa perjanjian kerjanya dari tanggal 1 November 2017 sampai dengan selesai. Dalam perjanjian kerja yang telah disepakati, gaji yang diterima setiap bulannya adalah Rp 2.173.000,00. Gaji tersebut akan dipotong lagi untuk biaya BPJS dan juga tidak ada pemberian tunjangan-tunjangan lainnya. Berdasarkan keterangannya, ketentuan UMK Kota Denpasar pada saat itu tidak diketahuinya. (Wawancara tanggal 20 November 2018).

\subsubsection{Sanksi Yang Diterima Pengusaha Jika Terdapat Penyimpangan Pada Pelaksanaa Upah Minimuum Terhadap Pekerja}


Hukum secara umum dapat diartikan sebagai himpunan peraturan baik tertulis maupun tidak yang berisikan larangan dan kebolehan yang apabila dilanggar dapat dikenakan sanksi. Sankisanksi merupakan bagian penutup yang penting di dalam hukum, sesuai dengan apa yang dikatakan oleh Tenberge dalam setiap hukum pastilah terdapat sanksi, hal ini bermaksa bahwa tidak ada kaidah hukum tanpa sanksi. ${ }^{10}$

Pada dasarnya pengusaha seharus membayar upah para pekerjanya tepat pada waktu yang sudah diperjanjikan. Jika pengusaha terlambat membayar dan/atau tidak membayar upah para pekerjanya, maka pengusaha akan dikenai denda/sanksi. Pengusaha juga dilarang untuk membayar upah pekerja lebih rendah dari upah minimum. Seperti yang sudah dijelaskan pada bab sebelumnya upah minimum terdiri atas :

a. Upah minimum berdasarkan wilayah provinsi atau kabupaten/kota;

b. Upah minimum berdasarkan sektor pada wilayah provinsi atau kabupaten/kota.

Ancaman pidana bagi pengusaha yang membayar upah pekerjanya di bawah upah minimum ialah pidana penjara yang paling singkat 1 (satu) tahun sedangkan yang paling lama 4 (empat) tahun dan/atau denda yang paling sedikit $\mathrm{Rp}$ 100.000.000,00 sedangkan yang paling banyak Rp 400.000.000,00.

Pengusaha dilarang membayar upah lebih rendah dari upah minimum. Pemerintah menetapkan upah minimum ini

\footnotetext{
${ }^{10}$ Ahmad Ali, 1996, Menguak Tabir Hukum, Chandra Pratama, Jakarta, h. 259
} 
berdasarkan kebutuhan hidup layak dan dengan memperhatikan produktivitas dan pertumbuhan ekonomi. Dalam hal ini di atur dalam Pasal 90 ayat (1) Undang-Undang No. 13 Tahun 2003 Tentang Ketenagakerjaan yang menyatakan: Pengusaha dilarang membayar upah lebih rendah dari upah minimum sebagaimana dimaksud dalam Pasal 89.

Berdasarkan hasil wawancara dengan I Wayan Rico Putra Negara, ST, selaku Development Manager PT Delta Duta Dewata, penyelesaian perselisihan hubungan industrial yang digunakan untuk menyelesaikan permasalahan dalam terlambatnya pengusaha memberikan upah pekerjanya sesuai UMK Kota ialah dilakukannya perundingan dan di bicarakan dengan baik-baik, sehingga pengusaha bisa menyelesaikan dan membayarkan upah pekerjanya dalam waktu kurang lebih 30 hari.

\section{PENUTUP}

\subsection{Kesimpulan}

1. Berdasarkan data-data yang telah diuraikan pada bab-bab sebelumnya, dapat disimpulkan :

1) Pelaksanaan Upah Minimum di PT Delta Duta Dewata belum di terapkan kepada beberapa pekerja alih dayanya, alhasil masih ada beberapa pekerjanya yang masih mendapatkan upah UMK Kota Denpasar Tahun 2017

2) Penyelesaian perselisihan hubungan industrial yang digunakan untuk menyelesaikan permasalahan dalam terlambatnya pengusaha memberikan upah pekerjanya sesuai UMK Kota 
ialah di lakukannya perundingan dan di bicarakan dengan baik-baik, sehingga pengusaha bisa menyelesaikan dan membayarkan upah pekerjanya dalam waktu kurang lebih 30 hari.

\subsection{Saran}

1) PT Delta Duta Dewata adalah salah satu perusahaan besar di Bali, sudah seharusnya perusahaan ini bekerja secara optimal dalam pelaksanaan pengupahan terhadap pekerjanya dan hendaknya lebih teliti dalam melakukan pengupahan agar permasalahan seperti ini tidak terulang kembali.

2) Agar tidak terjadi permasalahan dalam penupahan lagi, sebaikanya perusahaan selalu tepat waktu dalam pengambilan surat amandemen yang berisikan tentang uji petik yang dilaksanakan oleh PT PLN (Persero) Distribusi Bali. 


\section{DAFTAR PUSTAKA}

\section{Buku}

Ali, Ahmad, 1996, Menguak Tabir Hukum, Chandra Pratama, Jakarta

Nurachmad. Much, 2009, Tanya Jawab Seputar Hak-Hak Tenaga Kerja Kontrak (Outsourcing), Visimedia, Jakarta.

Subekti, 1987, Hukum Perjanjian, Intermasa, Jakarta.

Suprapto, 2013, "Metodologi Penelitian Ilmu Pendidikan dan IlmuIlmu Pengetahuan Sosial (Penelitian Kuantitatif dan Kualitatif Dilengkapi dengan Teknik Pengolahan Data dan Tabel Statistik)", CAPS, Bogor.

Udiana. I Made, 2011, Rekontruksi Pengaturan Penyelesaian Sengketa Penanaman Modal Asing, Udayana Press, Denpasar. , 2016, Kedudukan Dan Kewenangan Pengadilan Hubungan Industrial, Udayana University Press, Denpasar.

_ 2018, Industrialisai \& Tanggungjawab Pengusaha Terhadap Tenaga Kerja Terlibat Hukum, Udayana University Press, Denpasar.

Wijayanti. Asri, 2009, Hukum Ketenagakerjaan Pasca Reformasi, Sinar Grafika, Jakarta.

\section{Jurnal}

Ari Hernawan, 2016, "Keberadaan Uang Pesangon Dalam Pemutusan Hubungan Kerja Demi Hukum Di Peruswahaan Yang Sudah Menyelenggarakan Program Jaminan Pensiun", Kerta Partika , Vol.38, no. 1, April 2016, h. 1. https://ojs.unud.ac.id/index.php/kerthapatrika/article/vie w/21530 diakses tanggal 28 Januari 2019 pukul 22.30

Ni Made Pratiwi, 2017, "Hubungan Hukum Perusahaan Induk Berbentuk Perseroan Terbatas Dengan Anak Perusahaan Berbentuk Persekutuan Komanditer", Acta Comitas, Vol.02, 
no.01,

April

2017

h.

66.

https://ojs.unud.ac.id/index.php/ActaComitas/article/view $\angle 34258$ diakses tanggal 28 Januari 2019 pukul 22.23

\section{Peraturan Perundangan}

Indonesia, Undang-Undang Nomor 13 Tahun 2003 Tentang Ketenagakerjaan, Lembaran Negara Republik Indonesia Tahun 2003 Nomor 39, Tambahan Lembaran Negara Republik Indonesia Nomor 4279.

Peraturan Menteri Tenaga Kerja Nomor Per-01/Men/1999 tentang Upah Minimum jo. Surat Keputusan Menteri Tenaga Kerja dan Transmigrasi Nomor Kep-226/Men/2000 tentang Perubahan Pasal 1,3,4,8,11,20, dan 21 Peraturan Menteri Tenaga Kerja Nomor Per-01/Men/1999 Tentang Upah Minimum.

Keputusan Menteri Tenaga Kerja dan Transmigrasi Nomor : Kep. 220/Men/X/2004 Tentang Penyerahann Sebagaian Pelaksanaan Pekerja Kepada Perusahaan Lain.

Peraturan Gubernur Nomor 65 Tahun 2017 Tentang Penetapan Upah Minimum Kabupaten/Kota. 